Journal of Sustainable Development of Transport and Logistics

journal home page: https://jsdtl.sciview.net

Safonau, A., Vovk, Y., Lyashuk, O., \& Khudobei, R. (2020). Blending control of the trolleybus traction and brake drives to enhance the braking efficiency of a vehicle. Journal of

Sustainable Development of Transport and Logistics, 5(2), 49-61. doi:10.14254/jsdtl.2020.52.5 .

\title{
Blending control of the trolleybus traction and brake drives to enhance the braking efficiency of a vehicle
}

\author{
Andrei Safonau*, Yuriy Vovk ** ${ }^{\mathbb{D}}$, Oleg Lyashuk**D, Roman Khudobei ** \\ * Mechanical Engineering Faculty, Belarusian National Technical University, \\ 65 Independence Avenue, 220013 Minsk, Belarus \\ deanmef@bntu.by \\ ** Department of Automobiles, Ternopil Ivan Puluj National Technical University, \\ 56 Ruska str., 46001 Ternopil, Ukraine \\ vovkyuriy@ukr.net; oleglashuk@ukr.net;roman.khudobei@gmail.com
}

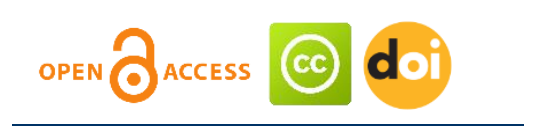

\section{Article history:}

Received: June 06, 2020

1st Revision: September 23, 2020

Accepted: November 05, 2020

\section{DOI:}

10.14254/jsdtl.2020.5-2.5

\begin{abstract}
Widespread usage of emission free public transport is the preferred strategy in many cities to reduce a congestion and pollution from the road traffic. The trolleybus is a kind of urban public transport, i.e. a fully electric vehicle, which is considered as a promising tool to enhance the efficiency of public transport and to attain the goals of sustainable development and quality of city life. The operation control of service brake system and secondary brake system (the braking torque of traction electric motor) is realized with help of one pedal in the trolleybus. Thus, there are modes of the joint operation for these systems during the braking process. Authors focus on the development of rule-based algorithm for the blending control of traction electric motor and anti-lock braking system to enhance the overall braking efficiency of a vehicle. The mathematical model of the trolleybus braking dynamics was developed for this purpose. Test bench and ride tests on different road surfaces were carried out to determine the parameters of vehicle braking efficiency and to validate the developed mathematical model. The corresponding experimental data were used to analyse the efficiency of proposed rule-based strategy for the blending control of traction electric motor and anti-lock braking system of the trolleybus. As a result, the availability of proposed control algorithm is confirmed, which secures the required braking efficiency and provides a high braking stability of the vehicle.
\end{abstract}

Keywords: trolleybus, anti-lock braking system, traction control. 


\section{Introduction}

Due to the present politics caused by alarming reports all over the world, environmentally friendly transport systems are called for in order to reduce emissions in urban areas partly caused by heavyduty traffic. The heavy-duty traffic is not only causing long term damages to the global eco system but is also polluting an air in cities with smog and causing noise which is affecting citizens negatively (Environmental Protection UK, 2020).

Environmental conditions in densely populated cities and also operating costs for vehicles with internal combustion engine demand a development of new conception of urban public transport as evidenced by European commission activity which supports financially scientific projects in this area (TROLLEY Project, 2010; The Publications Office of the European Union, 2011).

The main strategy of EU cities related to reaching goals of sustainable development and quality of life with respect to transport systems is implemented by pursuing the policy based on population mobility realization principle in addition to limited use of passenger cars. A state-of-the-art trolleybus, as kind of the urban public transport, is an efficient tool for attaining goals of sustainable development and quality of life, especially in areas of small and mid-sized cities. The trolleybus subsystem has a set of technical and technological, ecological, and economical advantages over other passenger transport subsystems (Tica, 2011; Bjorklund, 2000; Brown, 2001; Trolleybus and Gas ..., 2010; Romana, 2010).

Public transport as a whole should correspond to requirements of normative regulating documents (Regulations No. 13(10) EEC UNO; Regulations No. 36(03) EEC UNO; Regulations No. 51(02) EEC UNO; Regulations No. 107(02) EEC UNO) and should secure:

- high reliability and traffic safety;

- provision of maximum comfort for passengers on retention of minimal freight charges;

- demanded rate, traffic interval and passenger turnover;

- high manoeuvrability, towing performance and dynamic characteristics during operating in urban road traffic;

- minimal noise and maintenance of ecological demands.

It is obvious that the adequacy to such requirements is closely associated with the efficiency of traction and brake drives, which in turn depend on the correct scheme and design of these vehicle systems and the corresponding control algorithms.

As is well known, the operation control of a service brake system and secondary brake system (motor braking) is realized in trolleybus with help of one pedal. Consequently, there are modes of their joint operation during the braking of a vehicle.

The results of road tests of low-floor trolleybus produced at OJSC "BELKOMMUNMASH", Belarus, confirm that the control algorithm is demanded for the blending control of these vehicle systems during a braking to achieve the high braking efficiency of a vehicle (Figure 1).

Figure 1: Relative angular velocities of the driving wheels during emergency braking of articulated trolleybus on a wet asphalt surface using common algorithm to control the traction and brake drives

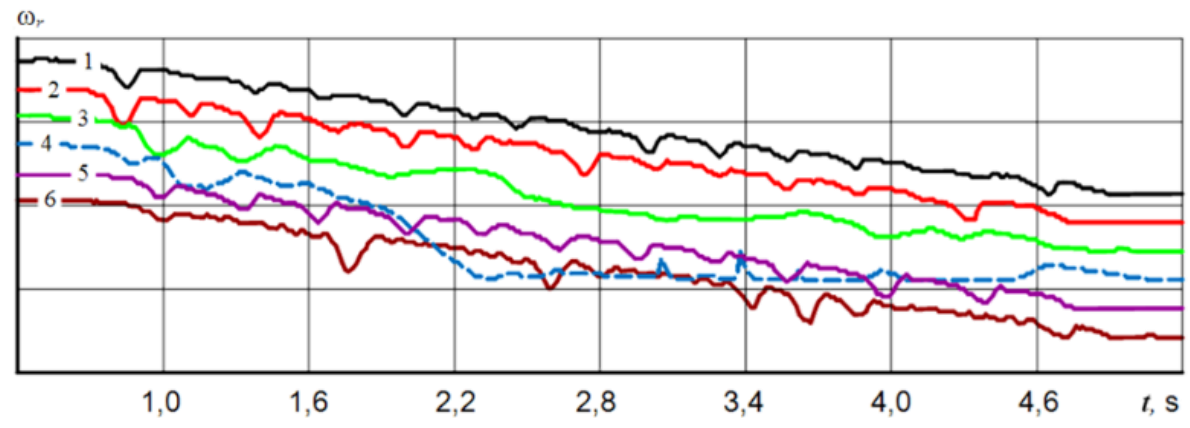


1, 2: wheels of the front driven axle; 3,4 : wheels of the driving axle; $5,6:$ wheels of the trolleybus semitrailer

Referring to Figure 1, the sharp decrease in angular velocity of one driving wheel of trolleybus is evident after 2,1 s from the beginning of braking on a wet asphalt surface in case of joint operation of service and secondary brake systems. There is such process in spite of the operation of common antilock braking system (ABS) until the complete stop of a trolleybus.

The literature survey confirms the advisability and urgency of the research activity aimed to develop the control algorithm for a blending control of the traction and brake drives to achieve high braking efficiency of the trolleybus. The corresponding information analysis also shows that the blending control of vehicle traction and brake drives will provide a possibility for the regenerative braking function and unloading wheel brakes (Toth-Antal, 2011).

The paper is organized as follows. The first section of the paper is devoted to developed mathematical model of trolleybus braking dynamics. This model is used to create the control algorithm for the blending control of the trolleybus traction and brake drives.

The scheme and detailed description of the proposed control algorithm is presented in the section 3 .

Third issue of the paper contains description of the test procedure and results of experimental tests aimed to analyse the trolleybus braking dynamics in case of usage of the developed control algorithm for the blending control of trolleybus traction and brake drives.

\section{Mathematical model of trolleybus braking dynamics}

The mathematical model of the braking dynamics of articulated trolleybus is used to develop the control algorithm for the blending control of trolleybus traction and brake drives (Figure 2).

Figure 2: Scheme of vehicle model

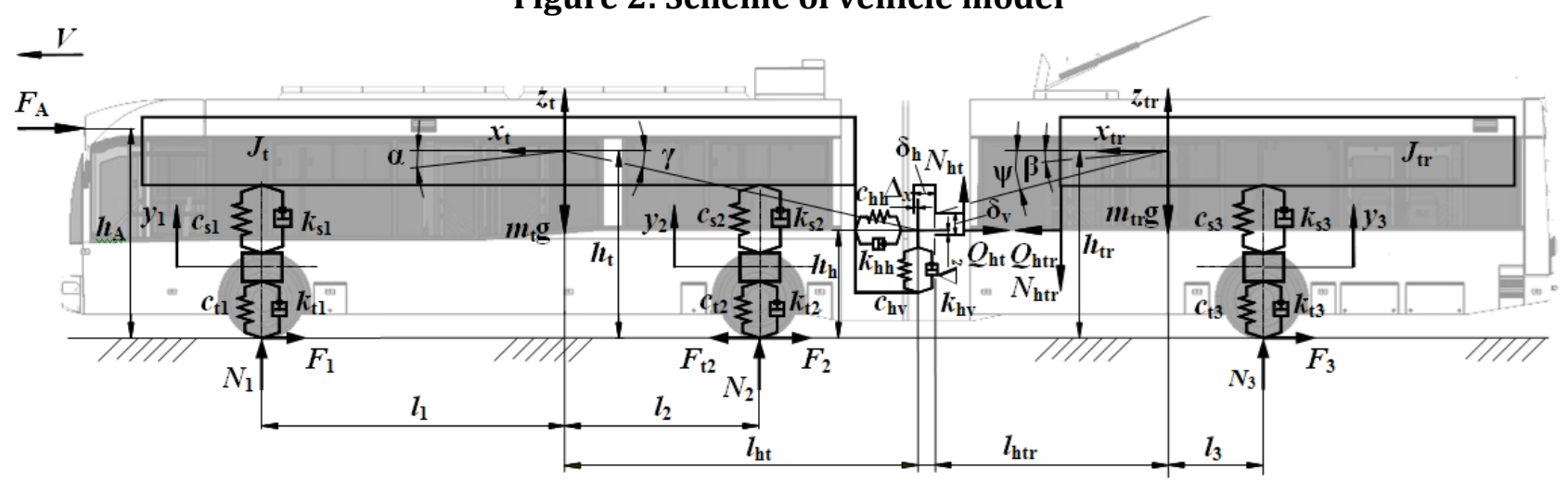

The developed model is based on following hypotheses:

- tractor and trailer have symmetrical weight distribution and don't accomplish lateral oscillations;

- vehicle axles are considered as point masses which have one degree of freedom and move around the vertical axle;

- tractor and trailer move in straight lines;

- stiffness characteristics of tires and suspensions are linear.

In accordance with the scheme shown in Figure 2 the tractor moving is described by following differential equations:

$$
m_{\mathrm{t}} \ddot{x}_{\mathrm{t}}=F_{t 2}-F_{1}-F_{2}-F_{\mathrm{A}}-Q_{\mathrm{ht}}
$$




$$
\begin{gathered}
m_{\mathrm{t}}^{\mathrm{s}} \ddot{z}_{\mathrm{t}}=N_{\mathrm{ht}}-c_{\mathrm{s} 1}\left(z_{\mathrm{t}}-l_{1} \sin \alpha-y_{1}\right)- \\
-c_{\mathrm{s} 2}\left(z_{\mathrm{t}}+l_{2} \sin \alpha-y_{2}\right)- \\
-k_{\mathrm{s} 1}\left(\dot{z}_{\mathrm{t}}-l_{1} \dot{\alpha} \cos \alpha-\dot{y}_{1}\right)- \\
-k_{\mathrm{s} 2}\left(\dot{z}_{\mathrm{t}}+l_{2} \dot{\alpha} \cos \alpha-\dot{y}_{2}\right) \\
J_{\mathrm{t}} \ddot{\alpha}=N_{\mathrm{ht}} l_{\mathrm{ht}}-\left(F_{1}+F_{2}-F_{\mathrm{t} 2}\right) h_{\mathrm{t}}- \\
-F_{\mathrm{A}}\left(h_{\mathrm{A}}-h_{\mathrm{t}}\right)+Q_{\mathrm{ht}}\left(h_{\mathrm{t}}-h_{\mathrm{h}}\right)+ \\
+c_{\mathrm{s} 1} l_{1} \cos \alpha\left(z_{\mathrm{t}}-l_{1} \sin \alpha-y_{1}\right)- \\
-c_{\mathrm{s} 2} l_{2} \cos \alpha\left(z_{\mathrm{t}}+l_{2} \sin \alpha-y_{2}\right)+ \\
+k_{\mathrm{s} 1} l_{1} \cos \alpha\left(\dot{z}_{\mathrm{t}}-l_{1} \dot{\alpha} \cos \alpha-\dot{y}_{1}\right)- \\
-k_{\mathrm{s} 2} l_{2} \cos \alpha\left(\dot{z}_{\mathrm{t}}+l_{2} \dot{\alpha} \cos \alpha-\dot{y}_{2}\right) \\
m_{1} \ddot{y}_{1}=-c_{\mathrm{t} 1}\left(y_{1}-h_{1}\right)+c_{\mathrm{s} 1}\left(z_{\mathrm{t}}-l_{1} \sin \alpha-y_{1}\right)- \\
-k_{\mathrm{t} 1}\left(\dot{y}_{1}-\dot{h}_{1}\right)+k_{\mathrm{s} 1}\left(\dot{z}_{\mathrm{t}}-l_{1} \dot{\alpha} \cos \alpha-\dot{y}_{1}\right) \\
m_{2} \ddot{y}_{2}=-c_{\mathrm{t} 2}\left(y_{2}-h_{2}\right)+c_{\mathrm{t} 2}\left(z_{\mathrm{t}}+l_{2} \sin \alpha-y_{2}\right)- \\
-k_{\mathrm{t} 2}\left(\dot{y}_{2}-\dot{h}_{2}\right)+k_{\mathrm{s} 2}\left(\dot{z}_{\mathrm{t}}+l_{2} \dot{\alpha} \cos \alpha-\dot{y}_{2}\right)
\end{gathered}
$$

The trailer motion is described by corresponding simultaneous equations:

$$
\begin{aligned}
& m_{\mathrm{tr}} \ddot{x}_{\mathrm{tr}}=Q_{\mathrm{htr}}-F_{3} \\
& m_{\mathrm{tr}}^{\mathrm{s}} \ddot{z}_{\mathrm{tr}}=-N_{\mathrm{htr}}-c_{\mathrm{s} 3}\left(z_{\mathrm{tr}}+l_{3} \sin \beta-y_{3}\right)- \\
& -k_{\mathrm{s} 3}\left(\dot{z}_{\mathrm{tr}}+l_{3} \dot{\beta} \cos \beta-\dot{y}_{3}\right) \\
& J_{\mathrm{tr}} \ddot{\beta}=N_{\mathrm{htr}} l_{\mathrm{htr}}-Q_{\mathrm{htr}}\left(h_{\mathrm{tr}}-h_{\mathrm{h}}\right)+F_{3} h_{\mathrm{t}}- \\
& \quad-c_{\mathrm{s} 3} l_{3} \cos \beta\left(z_{\mathrm{tr}}+l_{3} \sin \beta-y_{3}\right)- \\
& \quad-k_{\mathrm{s} 3} l_{3} \cos \beta\left(\dot{z}_{\mathrm{tr}}+l_{3} \dot{\beta} \cos \beta-\dot{y}_{3}\right) \\
& m_{3} \ddot{y}_{3}=-c_{\mathrm{t} 3}\left(y_{3}-h_{3}\right)+c_{\mathrm{s} 3}\left(z_{\mathrm{tr}}+l_{3} \sin \beta-y_{3}\right)- \\
& -k_{\mathrm{t} 3}\left(\dot{y}_{3}-\dot{h}_{3}\right)+k_{\mathrm{t} 3}\left(\dot{z}_{\mathrm{tr}}+l_{3} \dot{\beta} \cos \beta-\dot{y}_{3}\right)
\end{aligned}
$$

The correlation between simultaneous equations is realized by means of $N_{h t}, N_{h t r}$ and $Q_{h t}, Q_{h t r}$. These parameters are calculated:

$$
\begin{aligned}
& Q_{\mathrm{ht}}=Q_{\mathrm{htr}}=\left\{\begin{array}{l}
-\Delta_{\mathrm{x}} c_{\mathrm{hh}}-\Delta_{\dot{\mathrm{x}}} k_{\mathrm{hh}}, \Delta_{\mathrm{x}}<0 \\
0,0 \leq \Delta_{\mathrm{x}} \leq \delta_{\mathrm{h}} \\
-c_{\mathrm{hh}} \cdot\left(\Delta_{\mathrm{x}}-\delta_{\mathrm{h}}\right)-\Delta_{\dot{\mathrm{x}}} \cdot k_{\mathrm{hh}}, \Delta_{\mathrm{x}}>\delta_{\mathrm{h}}
\end{array}\right. \\
& N_{\mathrm{ht}}=N_{\mathrm{htr}}=\left\{\begin{array}{l}
-\Delta_{\mathrm{z}} c_{\mathrm{hv}}-\Delta_{\dot{\mathrm{z}}} k_{\mathrm{hv}}, \Delta_{\mathrm{z}}<0 \\
0,0 \leq \Delta_{\mathrm{z}} \leq \delta_{\mathrm{v}} \\
-c_{\mathrm{hv}}\left(\Delta_{\mathrm{z}}-\delta_{\mathrm{v}}\right)-\Delta_{\dot{\mathrm{z}}} \cdot k_{\mathrm{hv}}, \Delta_{\mathrm{z}}>\delta_{\mathrm{v}}
\end{array}\right.
\end{aligned}
$$

Parameters $\Delta_{x}, \Delta_{z}$ are defined as: 


$$
\begin{aligned}
& \Delta_{\mathrm{x}}=-x_{\mathrm{t}}+\left(b_{\mathrm{t}} \cos (\gamma-\alpha)-l_{\mathrm{ht}}\right)+x_{\mathrm{tr}}- \\
& -\left(l_{\mathrm{htr}}-b_{\mathrm{tr}} \cos (\psi+\beta)\right) \\
& \Delta_{\mathrm{z}}=z_{\mathrm{t}}+\left(b_{\mathrm{t}} \sin \gamma-b_{\mathrm{t}} \sin (\gamma-\alpha)\right)- \\
& -z_{\mathrm{tr}}+\left(b_{\mathrm{tr}} \sin (\psi+\beta)-b_{\mathrm{tr}} \sin \psi\right)
\end{aligned}
$$

Accordingly, the rate of deformation is calculated as:

$$
\begin{aligned}
& \left.\Delta_{\dot{\mathrm{x}}}=-\dot{x}_{\mathrm{t}}+b_{\mathrm{t}} \dot{\alpha} \sin (\gamma-\alpha)+\dot{x}_{\mathrm{tr}}-b_{\mathrm{tr}} \dot{\beta} \sin (\psi+\beta)\right) \\
& \Delta_{\dot{\mathrm{z}}}=\dot{z}_{\mathrm{t}}+b_{\mathrm{t}} \dot{\alpha} \cos (\gamma-\alpha)-\dot{z}_{\mathrm{tr}}+b_{\mathrm{tr}} \dot{\beta} \cos (\psi+\beta)
\end{aligned}
$$

The developed model allows investigate the dynamics of the straight line moving of a road train in case of tractor and semitrailer under different road conditions taking into account the distribution of vertical loads acting on vehicle axles. The model is usable also for the investigation of braking dynamics of the ordinary vehicle.

\section{Control algorithm for the blending control of trolleybus traction and brake drives}

One of the possible ways for a blending control of trolleybus traction and brake drives can be either complete switch-off of the electric motor (motor braking) in case of instant emergency braking. Another way is the creation of the corresponding braking torque by the electric traction motor of trolleybus, which can be completely compensated by the steadying effect from the electric motor and transmission units.

In the former case the torque input from the electric motor to driving wheels is close to zero, and the service brake system will fulfil the corresponding demands for the effective braking together with ABS. Passing of the emergency braking of the trolleybus with switched-off electric motor and characteristics of this process are shown in Figure 3. These data have been resulted from the road tests of low-floor trolleybus.

\section{Figure 3: Characteristics of the trolleybus emergency braking with switched-off electric motor}

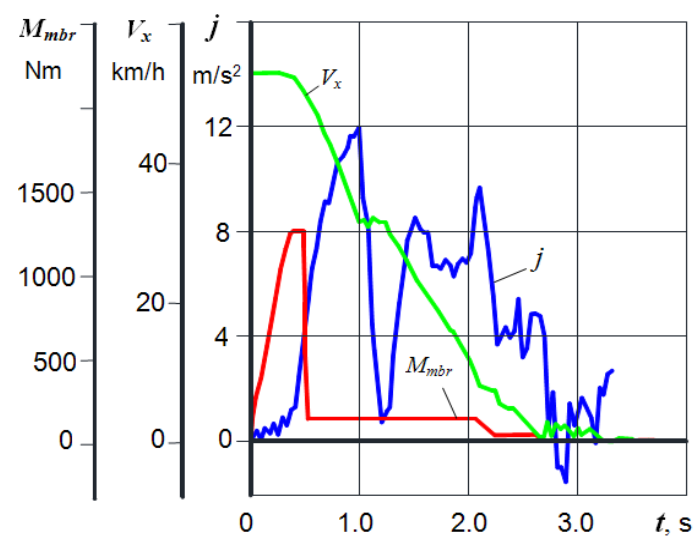

The braking process in such situation is attended with the sharp drop of the braking torque of electric motor to $120 \mathrm{Nm}$ (8.1\% of maximal value) when the deceleration of driving wheels becomes more than a set threshold which is equal to $3 \mathrm{~m} / \mathrm{s}^{2}$. Further ABS operation is accompanied by the typical control using corresponding pneumatic modulators of the service brake system. The slippage of driving wheels does not exceed $20 \%$ on asphalt surface in this case. Evidently, such control algorithm is not adaptive while the deceleration value depends on a road surface which is used as a set threshold. In case of low friction coefficient in the contact zone between road surface and wheels, wheel deceleration will be less than $3 \mathrm{~m} / \mathrm{s}^{2}$ and a system will not reduce the braking torque of electric motor during the period of critical slippage. If a set threshold is lowered, the electric motor operation would be poorer on the roads with high friction coefficient. 
In the latter case, keeping the electric motor in action during the emergency braking of a trolleybus will definitely enable the unloading wheel brakes and will also guarantee the possibility of regenerative braking in modern trolleybuses.

Thus, the limit value of the braking torque is bounded by the brake characteristic of electric motor and depends on the brake pedal displacement stup and the current angular velocity of electric motor shaft $\omega_{m}$. Hence, the braking torque of the electric traction motor is described as follow:

$$
M_{m b r}^{*}=f\left(\operatorname{stup}, \omega_{m}\right)
$$

The slippage value $S$ of driving wheels is used as the control parameter in proposed control algorithm for the blending control of trolleybus traction and brake drives. This algorithm secures the maximal using of the braking torque of the electric traction motor during the braking process of trolleybus. It should be underscored, that the choice of optimal method for the estimation of real vehicle longitudinal velocity is not in the scope of the current research activity. The main aim is to develop the control algorithm for the blending control of trolleybus traction and brake drives. The scheme of algorithm is depicted in Figure 4.

Figure 4: Control algorithm for the joint operation of trolleybus traction and brake drives

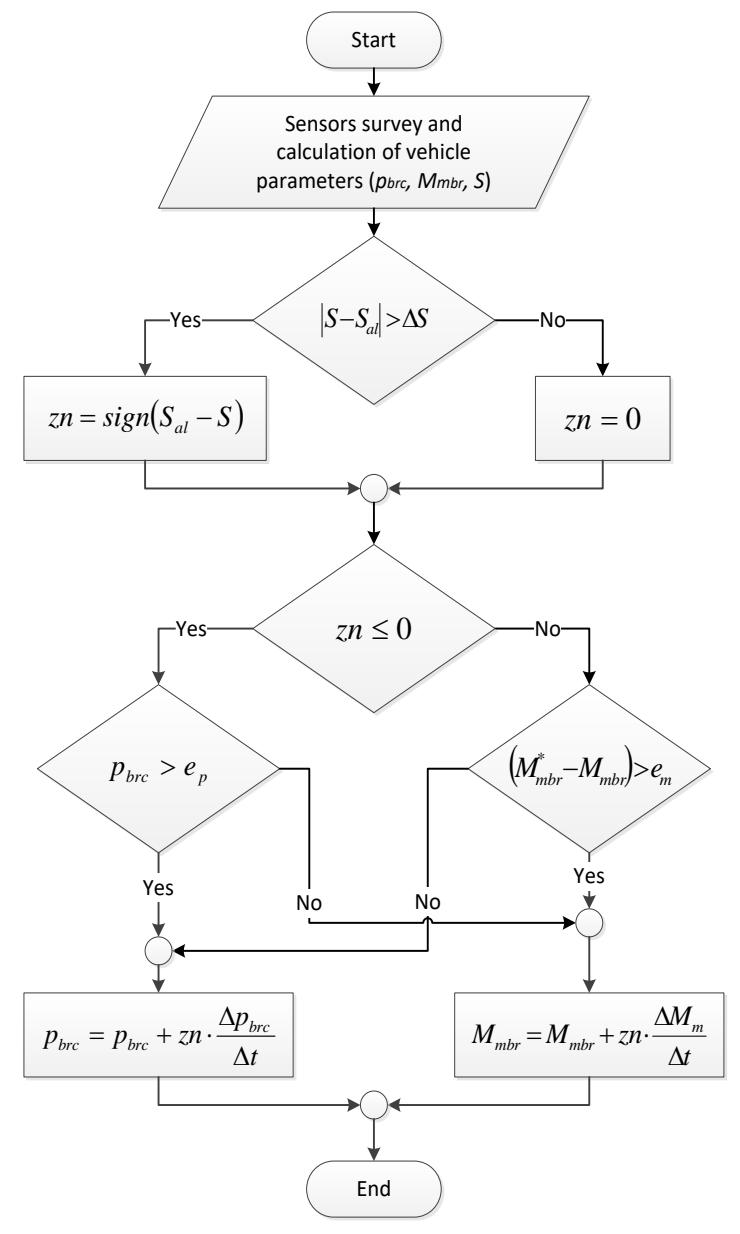

Values of $S_{\text {al }}$ and $\Delta S$ are determined in dependence of the maximal and minimal value of driving wheels slippage:

$$
\begin{aligned}
& S_{\text {al }}=\left(S_{\text {max }}+S_{\text {min }}\right) / 2 ; \\
& \Delta S=\left(S_{\text {max }}-S_{\text {min }}\right) / 2
\end{aligned}
$$


During the blending control of the trolleybus traction and brake drives a current value of driving wheels slippage is also determined. The braking torque of the electric motor and the pressure value at brake chambers of the driving wheels $p_{b r c}$ is reduced, increased or stabilized in dependence of the slippage value. The next order is retained in doing so.

1. $p_{b r c}$ is reduced primarily when $S$ is more than $S_{\max }$. Pressure release phase proceeds as long as $S$ is set to a range of allowed values. If $p_{b r c}$ becomes atmospheric and $S$ isn't set to a range of allowed values then the second phase comes and the braking torque of electric motor is reduced at that.

2. If $S$ is insignificant the operating order is inverse. $M_{m b r}$ is increased firstly. If it's not enough, i.e. slippage value is still not recover the demanded level, then $p_{b r c}$ is increased further.

3. If $S$ is in a range of allowed values so values of $M_{m b r}$ and $p_{b r c}$ are stabilized.

Consequently, the control algorithm should supply next interconnected characteristics during the blending control of trolleybus traction and brake drives as

$$
M_{m b r}=f\left(\operatorname{stup}, \omega_{\mathrm{m}}, S, p_{b r c}\right) ; p_{b r c}=f\left(\operatorname{stup}, S, M_{m b r}\right)
$$

The control of braking forces values for driven wheels is realized based on the common principles and algorithms.

Figure 5 shows the simulation results of trolleybus braking on different road surfaces using the developed mathematical model of braking dynamics of trolleybus and the control algorithm for blending control of its traction and brake drives.

Figure 5: Results of trolleybus braking process on different road surfaces using developed mathematical model and control algorithm

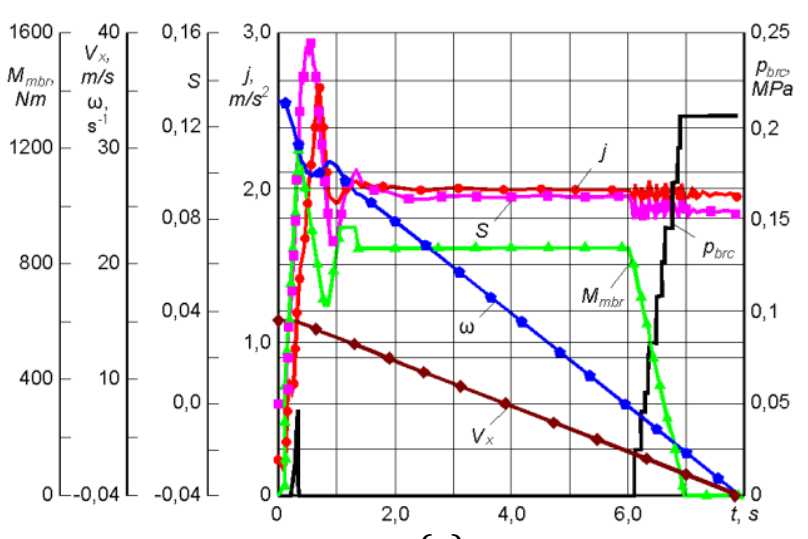

(a)

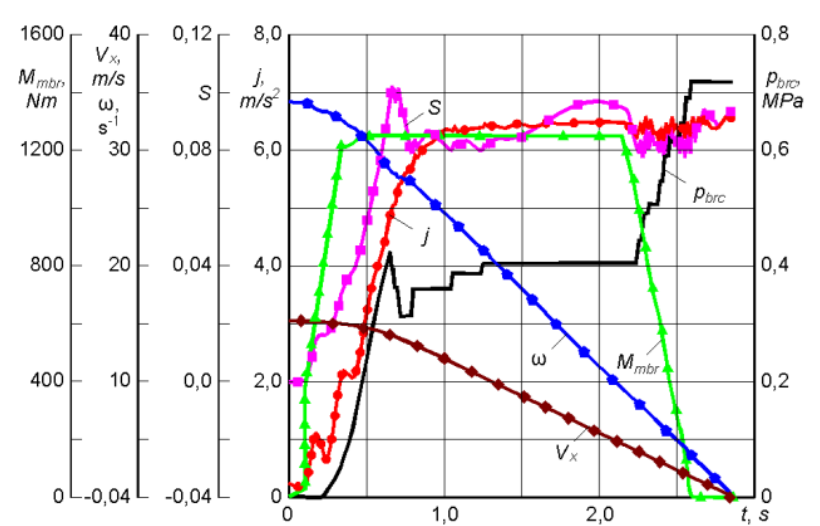

(b)

(a) snow-covered road; (b) asphalt road surface

According to Regulations (Regulations No. 13(10) EEC UNO) one of the main parameters of a vehicle brake system efficiency as well as ABS operation is the mean value of limiting deceleration $j$ which is determined during the braking on road surfaces with a high friction coefficient. The next main parameter is the coefficient of realized friction $k_{\phi}$ on different road surfaces. Authors mean that this parameter is determined as

$$
k_{\phi}=\frac{j}{g \cdot \phi}
$$


It follows from the Figure 5 (a) that the deceleration value $j$ is equal to $6.4 \mathrm{~m} / \mathrm{s}^{2}$ during the braking on the asphalt road surface. It should be mentioned, that the deceleration value should be no less than $4 \mathrm{~m} / \mathrm{s}^{2}$ for such vehicle type in this case (Regulations No. 13(10) EEC UNO). And the required value of the coefficient of realized friction $k_{\phi}$ should be no less than 0.75 (Regulations No. 13(10) EEC UNO). Accordingly, $k_{\phi}$ equals 0.77 on the asphalt road surface and is equal to 0.8 on a rolled snow road. Consequently, the correspondent results of computer simulation show:

- availability of the proposed control algorithm for blending control of the trolleybus traction and brake drives. It secures the required efficiency of the trolleybus brake system;

- high braking efficiency of the trolleybus is retained on different road surfaces;

- good operation consistency of the traction and brake drives and the possibility for integration of these systems in uniform one for the trolleybus braking control.

\section{Experimental investigation of trolleybus braking dynamics}

Road tests of low-floor trolleybus aimed to determine the parameters of braking efficiency during the blending control of trolleybus traction and brake drives using proposed control algorithm. Validation of developed mathematical model of the trolleybus braking dynamics also was evaluated during these tests. The scheme of the trolleybus brake system is presented in Figure 6.

Figure 6: Scheme of the trolleybus brake system

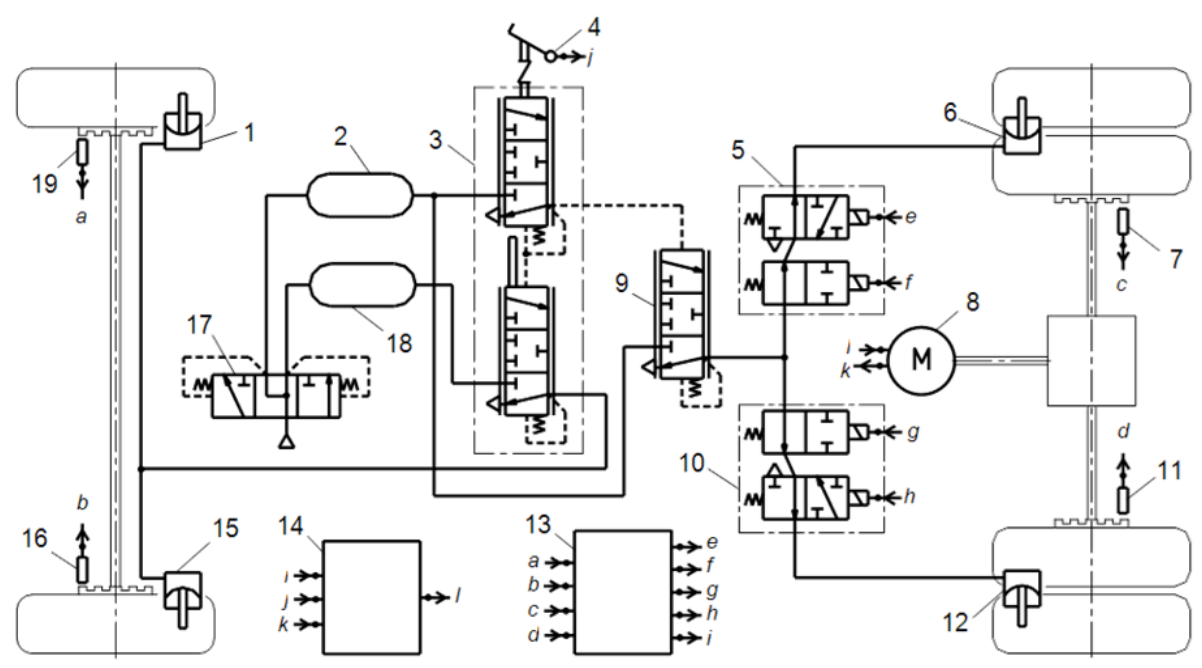

a-l: input and output signals;

$1,6,12,15$ : brake chambers; 2,18 : reservoirs; 3 : two-sectional brake valve; 4: sensor of brake pedal displacement; 5, 10: ABS modulators; 7, 11, 16, 19: wheel speed sensors; 8: traction electric motor; 9: acceleration valve; 13: ECU of ABS; 14: ECU of electric motor; 17: two-circuit protective valve

The arrangement of measuring equipment on trolleybus during the carrying out of road tests and its scheme is depicted in Figure 7.

Figure 7: Scheme and arrangement of measuring equipment 


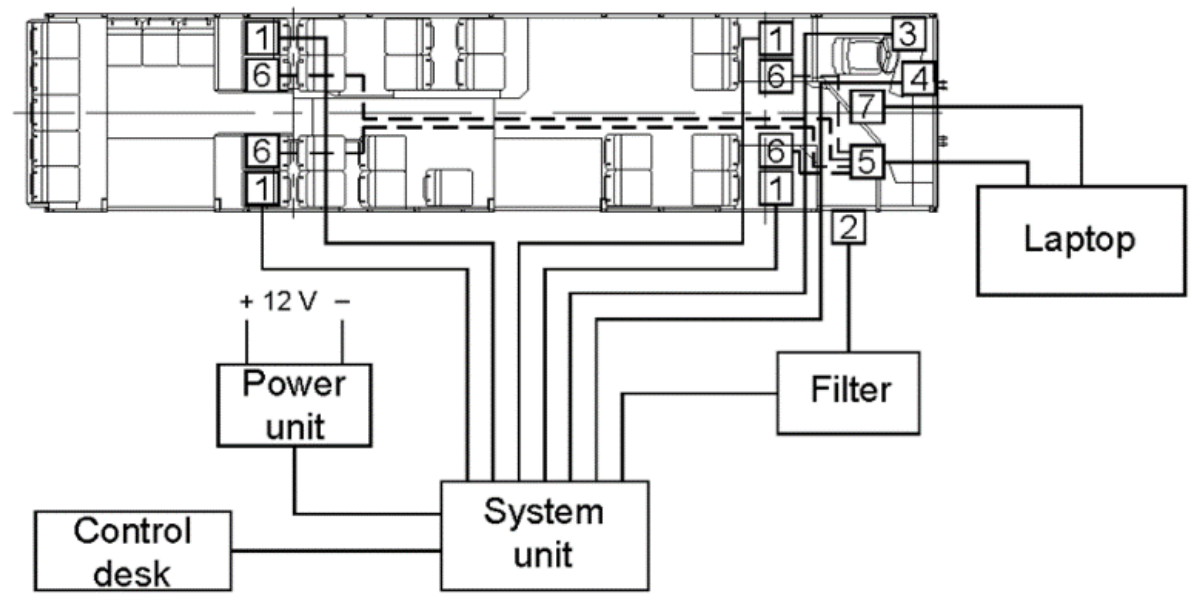

Note: 1: air pressure sensor at brake chamber; 2: optical sensor of trolleybus displacement, velocity and deceleration; 3: brake pedal sensor; 4 : digital display showing current values of measurable quantities; 5: ECU of the trolleybus ABS; 6: wheel speed sensor; 7: ECU of the trolleybus electric motor.

The measuring complex contained the set of Datron EEP-3 measuring equipment, inbuilt diagnostics and control system of the trolleybus, which is connected with on-board computer and ABS units, and allows measuring a travelled distance, velocity, deceleration, time of process acquisition, air pressure at brake chambers of driving wheels (Figure 8).

Figure 8: Measuring tooling Datron and its arrangement on trolleybus

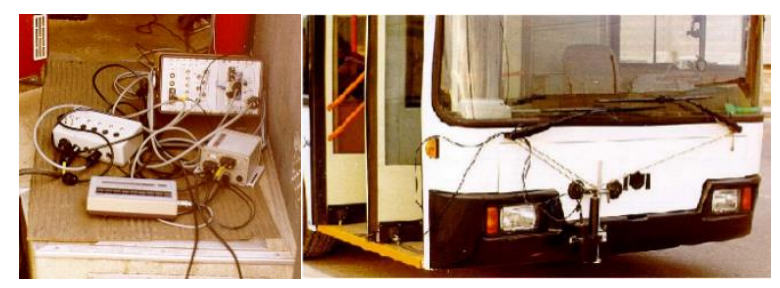

The process of the trolleybus emergency braking on the roads with a different value of friction coefficient was investigated during the carried out road tests.

Figure 9: Velocities of trolleybus driving and driven wheels during the emergency braking on a snow-covered road with conventional ABS control algorithm (a) and developed algorithm for the joint operation of trolleybus traction and brake drives (b)

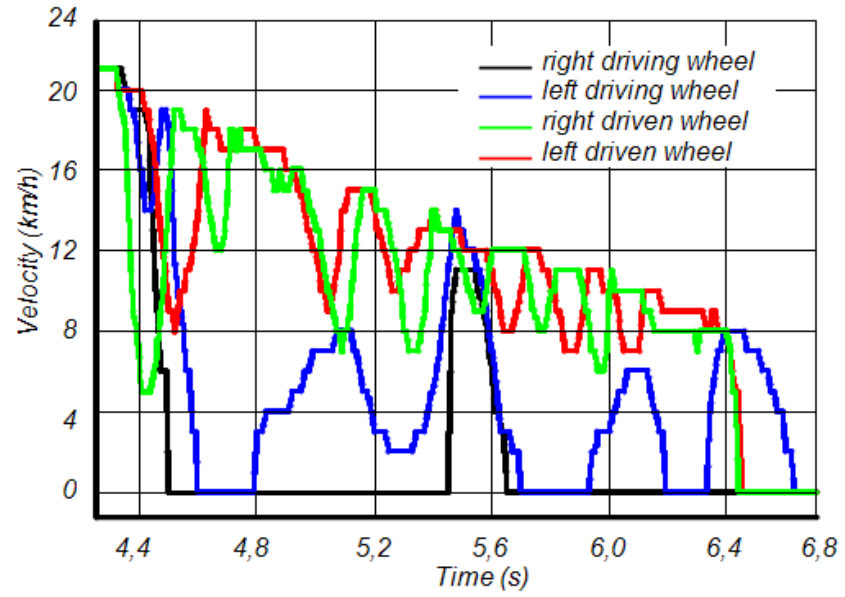

(a)

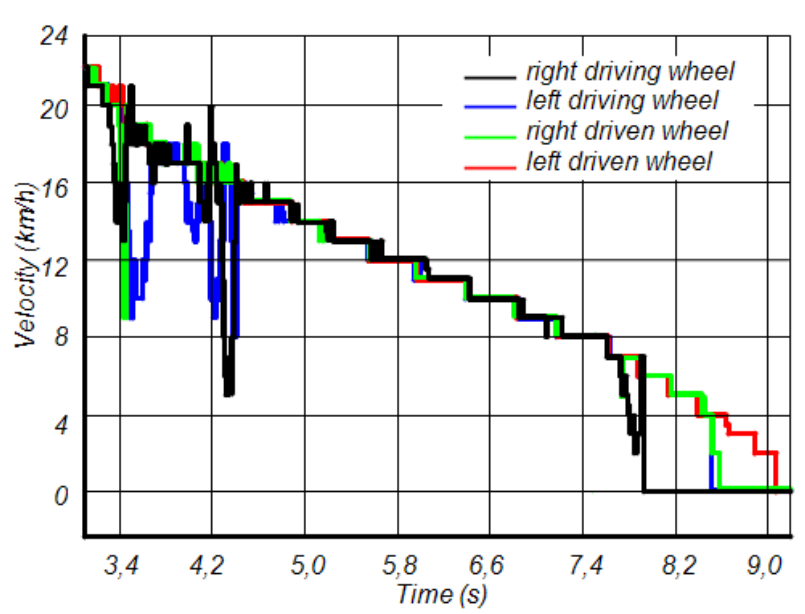

(b) 
As a result it was found out that the trolleybus driving and driven wheels are locked after 0,5 s since the braking start without ABS operation on a wet asphalt road surface. Driven wheels of the trolleybus aren't locked in case of common ABS operation during the emergency braking on a snowcovered road surface (Figure 9 (a)). As this takes place, the driving wheels are locked after 0,5 s since the braking start for a long periods while the braking torque of electric motor is out of control.

As shown in Figure 9 (b), the proposed control algorithm for the blending control of trolleybus traction and brake drives provides ABS operation in a cyclic mode without locking the wheels even during the emergency braking on a snow road surface until the reaching of the minimal trolleybus velocity (approx. $6 \mathrm{~km} / \mathrm{h}$ ) when ABS stops operating.

Figure 10 illustrates some characteristics of the trolleybus acceleration dynamics and allows estimate the efficiency of the proposed control algorithm during the operation of vehicle anti-slip regulation system (ASR). The efficiency is estimated using values of the driving wheels slippage of trolleybus equipped with ASR and without it. Referring to Figure 10, the slippage value of each driving wheel reaches $65 \%$ without ASR. And this value does not exceed $15 \%$ during ASR operation.

Figure 10: Velocities of trolleybus driving and driven wheels during the acceleration mode without ASR operation (a) and during the ASR operation using developed control algorithm (b)

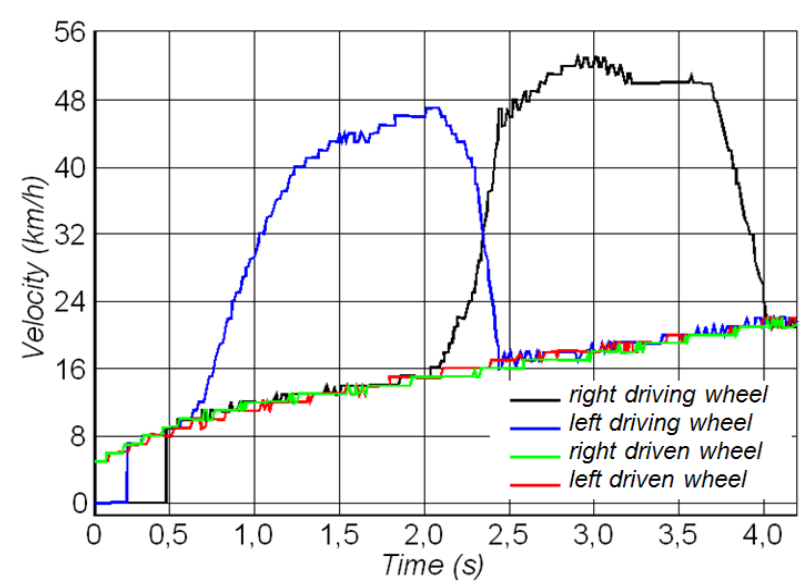

(a)

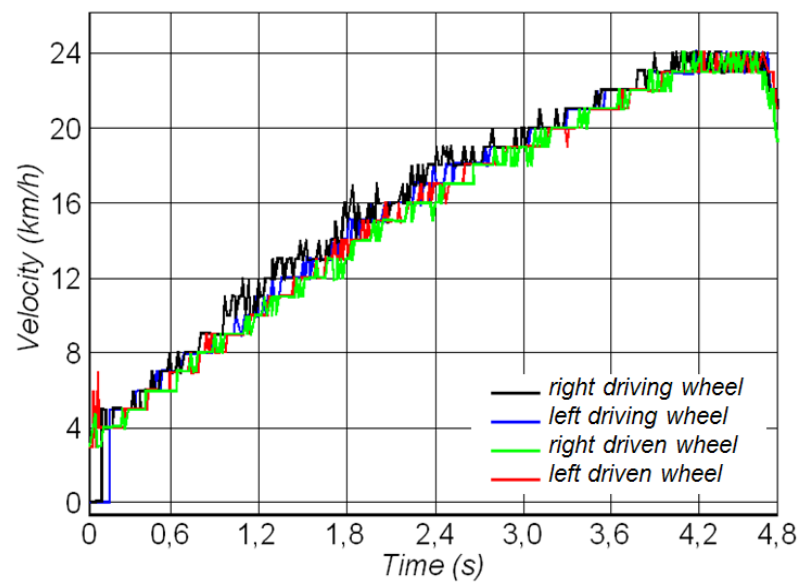

(b)

\section{Conclusions}

The developed mathematical model of the braking dynamics of articulated trolleybus described in the first section of the paper is usable for the investigation of braking and traction dynamics as well as of articulated trolleybus and ordinary vehicle.

The second problem investigated in the paper (section 2) is concerned with the development of the control algorithm for the blending control of trolleybus traction and brake drives to achieve high braking efficiency of a vehicle.

Computer simulation of the trolleybus braking were carried out on an asphalt surface and snowcovered road. It was estimated that the deceleration value is equal to $6.4 \mathrm{~m} / \mathrm{s}^{2}$ during the braking on an asphalt road surface. And the value of coefficient of realized friction equals 0.77 on an asphalt road surface and is equal to 0.8 on a rolled snow road.

The parameters of the trolleybus braking efficiency were estimated during the blending control of its traction and brake drives using the developed control algorithm during the carrying out road tests of low-floor trolleybus. Validation of the developed mathematical model of trolleybus braking dynamics was evaluated during these tests. The efficiency of trolleybus brake system was analysed in accordance to Regulations (9). It was indicated, that the proposed control algorithm provides ABS operation in a cyclic mode without locking the wheels even during the emergency braking on a snow road surface.

As a consequence, the availability of the proposed control algorithm was confirmed for the blending control of trolleybus traction and brake drives. It secures the required efficiency of the trolleybus brake system. Enhancement of braking process quality was shown, which is passed under optimal values of wheel slippage $-8-10 \%$. As a result, high braking stability is retained on different road 
surfaces. Good operation consistency of the traction and brake drives and the possibility for integration of these systems in uniform one was demonstrated for the trolleybus braking and traction control.

\section{Citation information}

Safonau, A., Vovk, Y., Lyashuk, O., \& Khudobei, R. (2020). Blending control of the trolleybus traction and brake drives to enhance the braking efficiency of a vehicle. Journal of Sustainable Development of Transport and Logistics, 5(2), 49-61. doi:10.14254/jsdtl.2020.5-2.5.

\section{References}

Environmental Protection UK. (2020). Car pollution. Retrieved February 16, 2011, from http://www.environmental-protection.org.uk/transport/car-pollution/.

TROLLEY Project. (2010). European Know-how \& cooperation. INTERREG IVB CENTRAL EUROPE Programme, European Commission.

The Publications Office of the European Union (2011). EGCI Ad-hoc Industrial Advisory Group, European Green Cars Initiative, Multi-annual roadmap and long-term strategy, European Commission, 2011.

Tica, S., Filipovic, S., Zivanovic, P., \& Bajcetic, S. (2011). Development of Trolleybus Passenger Transport Subsystems in Terms of Sustainable Development and Quality of Life in Cities. International Journal for Traffic and Transport Engineering, 1(4).196-205.

Bjorklund, S. (2000). New concepts for trolley buses in Sweden. The Board.

Brown, K. (2001). The benefits of clean, quiet, emission-free transit service: promoting the trolleybus in Vancouver. The TBus Group. Available online: http://www.tbus.org.uk/vtpn3.pdf.

Trolleybus and Gas bus Technology. Trends, Developments and Comparisons. (2010). NORCONSULT AS. Romana, L. (2010). Potential solutions for electric vehicles in bus and delivery traffic (Doctoral dissertation, Master's thesis. Aalto University, Department of Electrical Engineering, Espoo, Finland).

Regulations No. 13(10) EEC UNO, Geneva, Release 6.

Regulations No. 36(03) EEC UNO, Geneva, Release 3.

Regulations No. 51(02) EEC UNO, Geneva, Release 1.

Regulations No. 107(02) EEC UNO, Geneva, Release 1.

Toth-Antal, B. (2011). Brake resize investigation tool for regenerative braking. LCVTP Event.

Stang A. (2006). Enhancement of the electric transport on the base of usage of independent supply source, $\mathrm{PhD}$ thesis (in Russian). 


\section{Appendix 1}

\section{Notation}

\begin{tabular}{|c|c|}
\hline ABS & anti-lock braking system \\
\hline ASR & anti-slip regulation system \\
\hline$b_{t}, b_{t r}$ & distance between hitch point and the tractor and trailer centre of gravity respectively \\
\hline$c_{h h}, c_{h v}$ & hitch stiffness in horizontal and vertical direction respectively \\
\hline$c_{t i}, c_{s i}$ & longitudinal tire and suspension stiffness respectively of trolleybus axle \\
\hline$e_{M}$ & deadband for the braking torque of the electric motor \\
\hline$e_{p}$ & deadband for the pressure in a brake chamber \\
\hline$F_{A}$ & longitudinal aerodynamic resistance force \\
\hline$F_{i}$ & tire rolling resistance force \\
\hline$F_{t 2}$ & traction force of trolleybus driving axle \\
\hline$g$ & free-fall acceleration \\
\hline$h_{A}$ & height of aerodynamic centre \\
\hline$h_{h}$ & height of trailer hitch \\
\hline$h_{i} ; \dot{h}_{i}$ & height of road roughness's and a rate of its change respectively \\
\hline$h_{t}, h_{t r}$ & height of tractor and trailer centre of gravity respectively \\
\hline$k$ & coefficient depending on trolleybus capacity rate \\
\hline$I_{m r}$ & inertia moment of rotating parts of electric motor and transmission units \\
\hline$j$ & vehicle deceleration \\
\hline$J_{t}, J_{t r}$ & inertia moment of tractor and trailer body respectively \\
\hline$k_{h h}, k_{h v}$ & hitch damping in horizontal and vertical direction respectively \\
\hline$k_{t i}, k_{s i}$ & longitudinal tire damping and suspension damping of trolleybus axle respectively \\
\hline$k_{\varphi}$ & coefficient of realized friction \\
\hline$l_{h t}, l_{h t r}, l_{i}$ & geometrical parameters of trolleybus \\
\hline$M_{m}$ & traction torque of electric motor \\
\hline$M_{m b r}$ & braking torque of electric motor \\
\hline$M_{m b r}^{*}$ & $\begin{array}{l}\text { limit braking torque of electric motor depending on displacement of brake pedal and angular } \\
\text { velocity of electric motor shaft }\end{array}$ \\
\hline$m_{i}$ & unsprung mass of trolleybus axle \\
\hline$m_{t}, m_{t}^{s}$ & total and sprung tractor mass respectively \\
\hline$m_{t r}, m_{t r}^{s}$ & total and sprung trailer mass respectively \\
\hline$N_{h t}, N_{h t r}$ & the component of vertical force acting on tractor and trailer respectively from hitch \\
\hline$p_{b r c}$ & current value of pressure at brake chambers of driving wheels \\
\hline$p_{a}$ & atmospheric pressure at brake chambers of driving wheels \\
\hline$Q_{h t}, Q_{h t r}$ & the component of horizontal force acting on tractor and trailer respectively from hitch \\
\hline$S$ & current value of driving wheels slippage \\
\hline$S_{a l}$ & allowed mean value of driving wheels slippage \\
\hline$S_{\max }$ & maximal value of driving wheels slippage \\
\hline$S_{\min }$ & minimal value of driving wheels slippage \\
\hline
\end{tabular}




\begin{tabular}{ll}
\hline stup & displacement of brake pedal \\
$t$ & time \\
$V_{x}$ & trolleybus longitudinal velocity \\
$x_{t}, x_{t r}$ & horizontal displacement of tractor and trailer centre of gravity respectively \\
$y_{i}$ & vertical displacement of trolleybus axle \\
$z n$ & sign in dependence on slippage level ( $z n=1$ at high slippage value, $z n=-1$ at low slippage \\
& value and $z n=0$ - slippage value is normal) \\
$z_{t}, z_{t r}$ & vertical displacement of tractor and trailer centre of gravity respectively \\
$\alpha, \gamma$ & rotation angles of tractor body around an axis passing through its centre of gravity \\
$\beta, \psi$ & rotation angles of trailer body around an axis passing through its centre of gravity \\
$\delta_{h}, \delta_{v}$ & horizontal and vertical component respectively of hitch gap \\
$\varepsilon_{m}$ & angular deceleration of electric motor shaft \\
$\mu$ & friction coefficient in a contact between road surface and tire \\
$\omega$ & angular velocity of driving wheel \\
$\omega_{r}$ & relative angular velocity of driving wheel \\
$\omega_{m}$ & angular velocity of electric motor shaft \\
$\Delta_{x}, \Delta$ & horizontal and vertical component respectively of hitch compressive deformation \\
$\Delta S$ & range of allowed values of driving wheels slippage
\end{tabular}

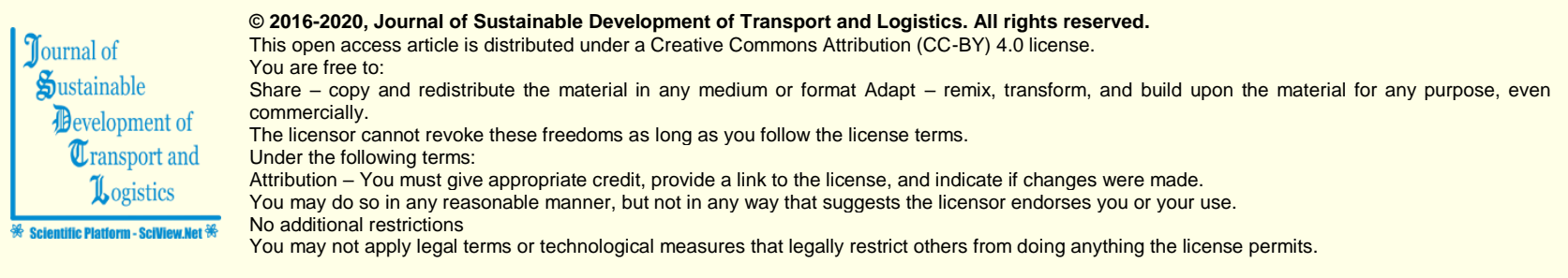

Journal of Sustainable Development of Transport and Logistics (ISSN: 2520-2979) is published by Scientific Publishing House "CSR", Poland, EU and Scientific Publishing House "SciView", Poland, EU

Publishing with JSDTL ensures:

- Immediate, universal access to your article on publication

- High visibility and discoverability via the JSDTL website

- Rapid publication

- Guaranteed legacy preservation of your article

- Discounts and waivers for authors in developing regions

Submit your manuscript to a JSDTL at https://jsdtl.sciview.net/ or submit.jsdtI@sciview.net 
